\title{
Characterization of Polycrystalline SiC Films Grown by HW-CVD using Silicon Tetrafluoride
}

\author{
Katsuya Abe, Yohei Nagasaka, Takahiro Kida, Tomohiko Yamakami, \\ Rinpei Hayashibe and Kiichi Kamimura,
}

Faculty of Engineering, Shinshu University, 4-17-1 Wakasato, Nagano 380-8553, Japan

\begin{abstract}
$\mathrm{SiC}$ films were synthesized by hot-wire chemical vapor deposition using a tungsten filament and a gas mixture of $\mathrm{SiF}_{4}$ and $\mathrm{CH}_{4}$. The etching of the substrate instead of the film growth occurred on the samples prepared using only source gases without $\mathrm{H}_{2}$ dilution. The atomic or molecular hydrogen was believed to control the density of radicals containing $\mathrm{F}$ in a gas phase or on a growth surface. Polycrystalline $3 \mathrm{C}-\mathrm{SiC}(111)$ films were successfully obtained at substrate temperatures lower than $500^{\circ} \mathrm{C}$ by using $\mathrm{H}_{2}$ dilution. The growth mode limited by source-gas supply was found to be important to obtain polycrystalline $\mathrm{SiC}$ films. The $\mathrm{SiC}$ film grown at higher deposition pressure was amorphous and contained no $\mathrm{Si}-\mathrm{H}_{\mathrm{x}}$ bonds but $6 \%$ fluorine. In $\mathrm{SiF}_{4} / \mathrm{CH}_{4} / \mathrm{H}_{2}$ system, the radicals containing $\mathrm{F}$ are considered to play very important roles in the reactions both on a growth surface and in a gas-phase.
\end{abstract}

\section{Keywords}

Hot-wire, $\mathrm{CVD}, 3 \mathrm{C}-\mathrm{SiC}, \mathrm{SiF}_{4}, \mathrm{H}_{2}$ dilution

\section{Introduction}

Silicon Carbide $(\mathrm{SiC})$ is a promising wide gap semiconductor material utilized in a wide variety of applications. Its superior physical and chemical properties make it attractive for power electronic and optoelectronic device applications. The crystalline $\mathrm{SiC}$ growth is generally carried out at very high temperatures higher than $1200^{\circ} \mathrm{C}$. This high growth temperature prevents the flexible design of the electronic devices.

Hydrogenated amorphous or microcrystalline $\mathrm{SiC}$ alloy films are also expected to be material for thin film solar cells. The a-SiC and $\mu \mathrm{c}-\mathrm{SiC}$ films could be prepared at the substrate temperatures lower than $300^{\circ} \mathrm{C}$ by plasma enhanced chemical vapor deposition (PECVD) and hot-wire (HW) CVD. Recently the low temperature epitaxial growth of $3 \mathrm{C}-\mathrm{SiC}$ was also reported [1]. In the $\mathrm{SiC}$ growth by PECVD, various $\mathrm{Si}$ sources, such as $\mathrm{SiH}_{4}$ [2], methylsilanes [3] and silicon halide [4], are used. $\mathrm{SiH}_{4}$ and methylsilanes are also applied to HW-CVD [5-6]. However, the SiC film growth by HW-CVD using silicon halide sources has not been reported.

In this work, the polycrystalline $\mathrm{SiC}$ films were grown at low temperature $\left(300-500^{\circ} \mathrm{C}\right)$ by $\mathrm{HW}-$ CVD using silicon tetrafluoride $\left(\mathrm{SiF}_{4}\right)$, and their structural properties were characterized.

\section{Experimental procedure}

The $\mathrm{Si}$ and $\mathrm{SiC}$ films were deposited on $\mathrm{Si}(001)$ and $\mathrm{Si}(111)$ substrates by a HW-CVD system using a "Z" shaped tungsten filament. The filament diameter and length were $0.5 \mathrm{~mm}$ and $150 \mathrm{~mm}$, 
respectively. The filament temperature and filament-substrate distance were maintained at $1750^{\circ} \mathrm{C}$ and $45 \mathrm{~mm}$, respectively. The substrates were cleaned using a ultrasonic treatment in acetone, etched by a 5\% hydrogen fluoride solution and rinsed in deionized water prior to loading into the CVD system. The growth chamber was evacuated to $2 \times 10^{-6}$ Torr by a turbo molecular pump. The source gases were $\mathrm{SiF}_{4}(>99.999 \%)$ and $\mathrm{CH}_{4}(>99.999 \%)$, and their flow rate was maintained at $5 \mathrm{sccm}$ by mass flow controllers. $\mathrm{H}_{2}(>99.99999 \%)$ was used as a diluent gas. For Si growth, the films were deposited with varying $\mathrm{H}_{2}$ flow rate from 0 to $150 \mathrm{sccm}$. For $\mathrm{SiC}$ growth, it was maintained at $100 \mathrm{sccm}$. The substrate temperature and growth pressure was varied from 300 to $500^{\circ} \mathrm{C}$ and from 0.5 to 4.5 Torr, respectively. The structural property and bonding configuration of the SiC films were characterized using X-ray diffractometry (XRD), Fourier transfer infrared absorption spectroscopy (FTIR) and X-ray photoelectron spectroscopy (XPS).

\section{Results and Discussion}

The Si films were grown using $\mathrm{SiF}_{4}$ and $\mathrm{H}_{2}$ at the substrate temperature of $400^{\circ} \mathrm{C}$ and the growth pressure of 1.5 Torr. Etching of the substrate surface was observed on the samples prepared using only $\mathrm{SiF}_{4}$ without $\mathrm{H}_{2}$ dilution. Similar results were reported in other works about $\mathrm{Si}$ film growth by plasma enhanced CVD using $\mathrm{SiF}_{4}$ [4,7]. The results indicate a strong etching reaction of radicals containing fluorine atoms generated by the decomposition of $\mathrm{SiF}_{4}$. In addition, it is suggested that the atomic or molecular hydrogen controls the density of radicals containing $\mathrm{F}$ in a gas phase. An example of the possible gas phase reactions is as follows [8]:

$\mathrm{F}+\mathrm{H}_{2} \rightarrow \mathrm{HF}+\mathrm{H}$

The SiC films were obtained using $\mathrm{H}_{2}$ dilution at the substrate temperatures of $300-500^{\circ} \mathrm{C}$. Figure 1 shows the dependence of XRD patterns on the substrate temperature. The films were deposited at the growth pressure of 1.5 Torr. A diffraction peak at $28^{\circ}$ originates in $\operatorname{Si}(111)$ substrate. A peak originating in $3 \mathrm{C}-\mathrm{SiC}(111)$ was measured at $36^{\circ}$ in the films grown at the temperature higher than $400^{\circ} \mathrm{C}$. Thus the polycrystalline $3 \mathrm{C}-\mathrm{SiC}$ films were obtained at the temperature lower than $500^{\circ} \mathrm{C}$. In addition, the similar results were obtained in the XRD patterns of the films grown on the $\mathrm{Si}(001)$ substrate. It is implied that the $\mathrm{SiC}$ films are grown in the 3D island growth mode instead of the epitaxial like growth, because of no dependence of XRD pattern on the substrate difference.

The dependence of IR spectra on the substrate temperature is indicated in Fig. 2. A remarkable absorption peak at $800 \mathrm{~cm}^{-1}$ originating in Si-C stretching mode was detected. The sharp Si-C peak of the film grown at $300^{\circ} \mathrm{C}$ suggests the crystallization of the film [9].

In our samples, no $\mathrm{Si}-\mathrm{H}_{\mathrm{x}}$ peak at around $2000 \mathrm{~cm}^{-1}$ was detected. It is widely known that the $\mathrm{H}$ concentration in the Si films grown by HW-CVD is comparative low value of 1-10\% [10-11]. However, the $\mathrm{H}$ concentration in our samples was almost $0 \%$. The result suggests that the radicals containing $\mathrm{F}$ remove the $\mathrm{H}$ atoms on the growth surface. Another possible reason is the temperature of the growth surface. In this work, the substrate temperature was measured by a thermocouple located at the heater block under the substrate holder. Thus it is probable that the surface temperature increases up to higher than $500^{\circ} \mathrm{C}$, which is the temperature of $\mathrm{H}$ thermal desorption from the Si surface, by thermal radiation of the hot wire. 
Figure 3 shows the dependence of growth rate on the deposition pressure. The films were deposited at $400^{\circ} \mathrm{C}$. The growth rate increased with increasing pressure up to 1.5 Torr, and saturated at the pressure higher than 3.0 Torr. Thus, the growth reaction is limited by source-gas supply at the pressure lower than 1.5 Torr, and limited by surface reactions at the pressure higher than 3.0 Torr.

XRD patterns of the $\mathrm{SiC}$ films grown on $\mathrm{Si}(111)$ at various growth pressures are shown in Fig. 4. The $3 \mathrm{C}-\mathrm{SiC}(111)$ peak was measured in the patterns of the films grown at 1.0 and 1.5 Torr. It was confirmed by FTIR measurements that the structure of the films grown at pressure higher than 3.0 Torr was amorphous. The results indicated that the growth mode limited by source-gas supply is required to obtain the $\mathrm{SiC}$ films with high crystallinity. In the growth limited by surface reactions, the precursors bond at unstable sites on the growth surface because of insufficient surface diffusion length, resulting in amorphous film growth.

Generally, atomic hydrogen has many very important roles, such as removing weak bonds and passivating dangling bonds on the growth surface, in the low temperature CVD of Si films [1213]. In $\mathrm{SiF}_{4} / \mathrm{CH}_{4} / \mathrm{H}_{2}$ system, the radicals containing $\mathrm{F}$ also seemed to play important roles in the growth mechanism. Figure 5 indicates XPS spectra of the $\mathrm{SiC}$ films grown at 1.5 and 4.5 Torr. The substrate temperature was maintained at $400^{\circ} \mathrm{C}$. No fluorine peak was observed in the XPS spectrum of the polycrystalline $\mathrm{SiC}$ film grown at $1.5 \mathrm{~T}$ orr. On the other hands, apparent fluorine peaks were detected in the amorphous $\mathrm{SiC}$ film grown at 4.5 Torr. The concentration of fluorine was estimated to be $6 \%$ from the peak area of the spectrum. The results suggest that crystallinity of the $\mathrm{SiC}$ film is strongly affected by the radicals containing $\mathrm{F}$ both in the gas-phase and on the growth surface. In order to improve the film crystallinity, the effects of the radicals containing $\mathrm{F}$ must be examined and followed by careful discussions of growth kinetics.

\section{Conclusion}

The polycrystalline 3C-SiC(111) films were successfully obtained at substrate temperatures lower than $500^{\circ} \mathrm{C}$ by HW-CVD using $\mathrm{H}_{2}$ dilution of $\mathrm{SiF}_{4}$ and $\mathrm{CH}_{4}$. No film growth occurred without $\mathrm{H}_{2}$ dilution because of the strong etching reaction of radicals containing $\mathrm{F}$ generated by decomposition of $\mathrm{SiF}_{4}$. The growth mode limited by source-gas supply was required to obtain the polycrystalline $\mathrm{SiC}$ films. It was found that the amorphous $\mathrm{SiC}$ film grown at higher growth pressure contained no $\mathrm{Si}-\mathrm{H}_{\mathrm{x}}$ bonds but $6 \%$ fluorine. The results suggested that the radicals containing F played very important roles both in gas-phase and on growth surface. 


\section{References}

1. K. Yasui, J. Eto, Y. Narita, M. Takata, T. Akahane, Jpn. J. Appl. Phys. 44 (2005) 1361.

2. D. Kuhman, S. Grammatica, F. Jansen, Thin Solid Films 177 (1989) 253.

3. D. S. Kim, Y. H. Lee, Thin Solid Films 283 (1996) 109.

4. G. Cicala, P. Capezzuto, G. Bruno, M. C. Rossi, Appl. Surf. Sci. 184 (2001) 66.

5. A. Kumbhar, S. B. Patil, S. Kumar, R. Lal, R. O. Dusane, Thin Solid Films 395 (2001) 244.

6. S. Miyajima, A. Yamada, M. Konagai, Jpn. J. Appl. Phys. 43 (2004) L1190.

7. T. Kamiya, K. Nakahata, C. M. Fortmann, I. Shimizu, J. Non-Cryst. Solids 266-269 (2000) 120.

8. A. N. Alcaraz, J. Codnia, M. L. Azcarate, J. Photochem. Photobiol. A: Chem. 165 (2004) 209.

9. Y. Sun and T. Miyasato, Jpn. J. Appl. Phys. 37 (1998) 5485.

10. A. H. Mahan, J. Carapella, B. P. Nelson, R. S. Crandall, I. Balberg, J. Appl. Phys. 69 (1991) 6728 .

11. A. Masuda, C. Niikura, Y. Ishibashi, H. Matsumura, Solar Energy Mater. Solar Cells 66 (2001) 259.

12. K. Abe, T. Watahiki, A. Yamada, M. Konagai, Jpn. J. Appl. Phys. 38 (1999) 3622.

13. K. Abe, T. Tsushima, M. Ichikawa, A. Yamada, M. Konagai, J. Non-Cryst. Solids 266-269 (2000) 105. 


\section{List of figure captions}

Fig. 1. The dependence of XRD patterns of $\mathrm{SiC}$ films on the substrate temperature. The films were grown at the growth pressure of 1.5 Torr.

Fig. 2. The dependence of IR spectra of SiC films on the substrate temperature. The films were grown at the growth pressure of 1.5 Torr.

Fig. 3. The dependence of growth rate on the growth pressure. The films were grown at the substrate temperature of $400^{\circ} \mathrm{C}$.

Fig. 4. XRD patterns of $\mathrm{SiC}$ films grown at various growth pressures. The films were grown at the substrate temperature of $400^{\circ} \mathrm{C}$.

Fig. 5. XPS spectra of SiC films grown at growth pressure of 1.5 and 4.5 Torr. The substrate temperature was maintained at $400^{\circ} \mathrm{C}$. 
Fig. 1

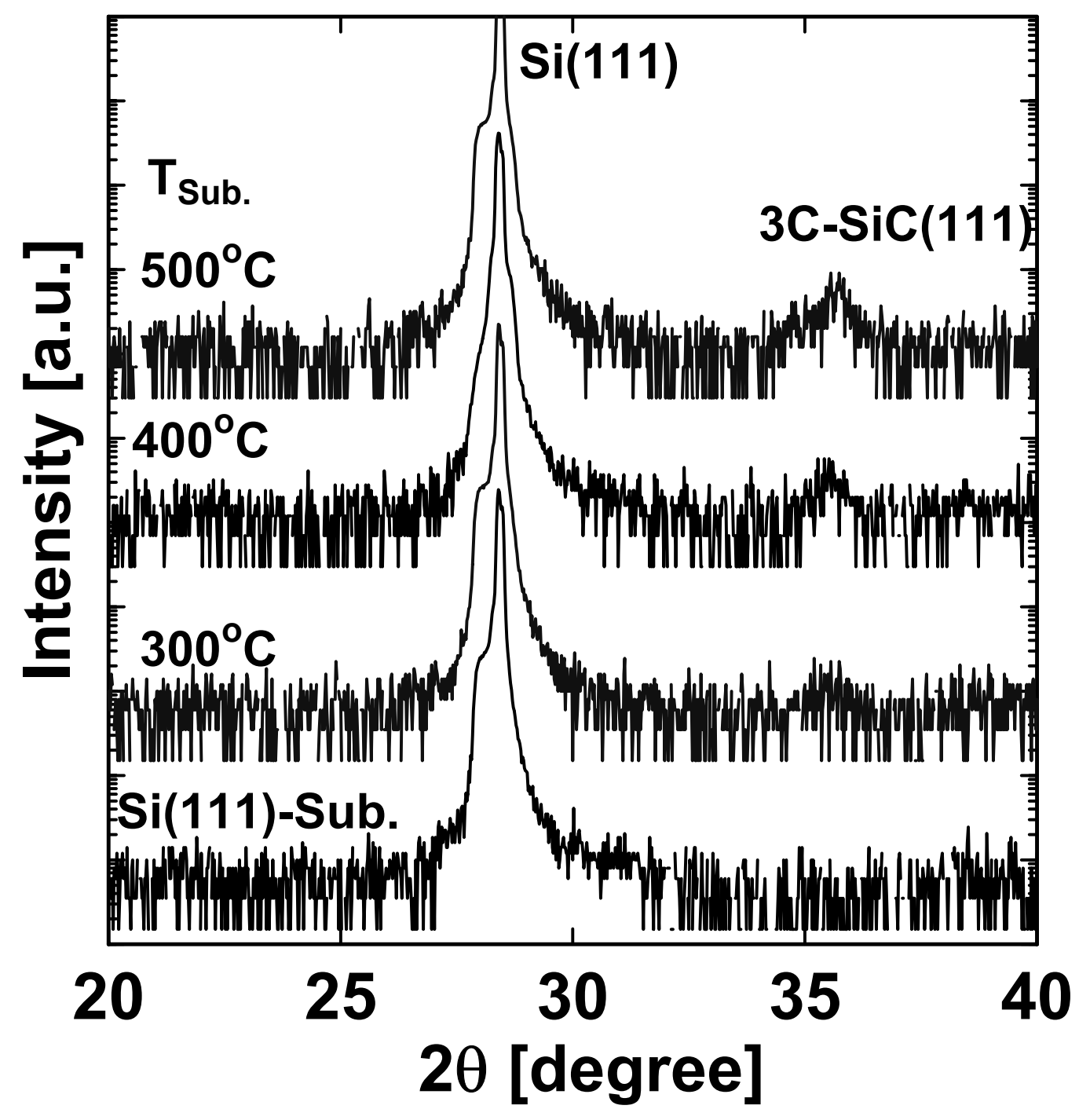


Fig. 2

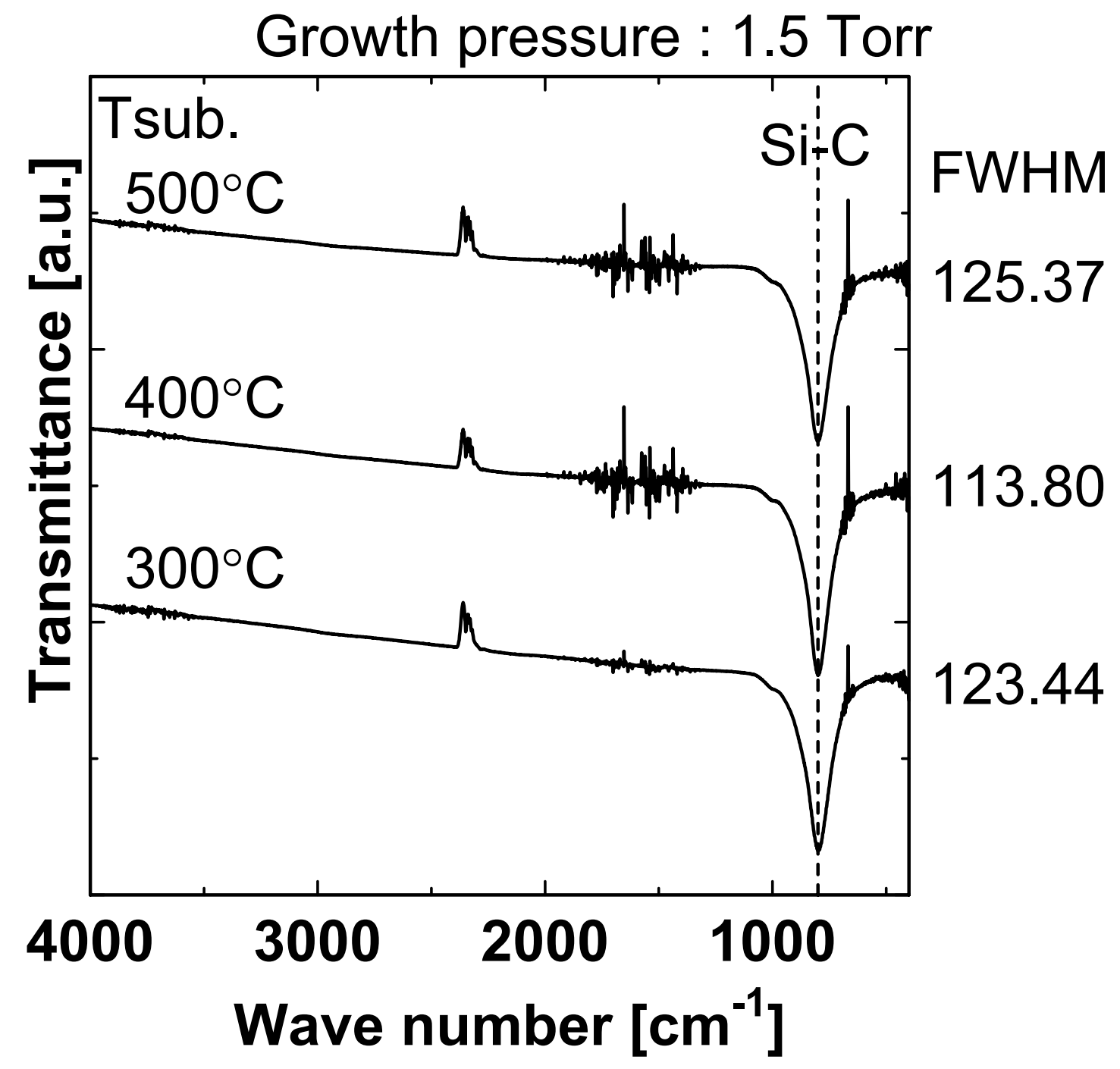


Fig. 3

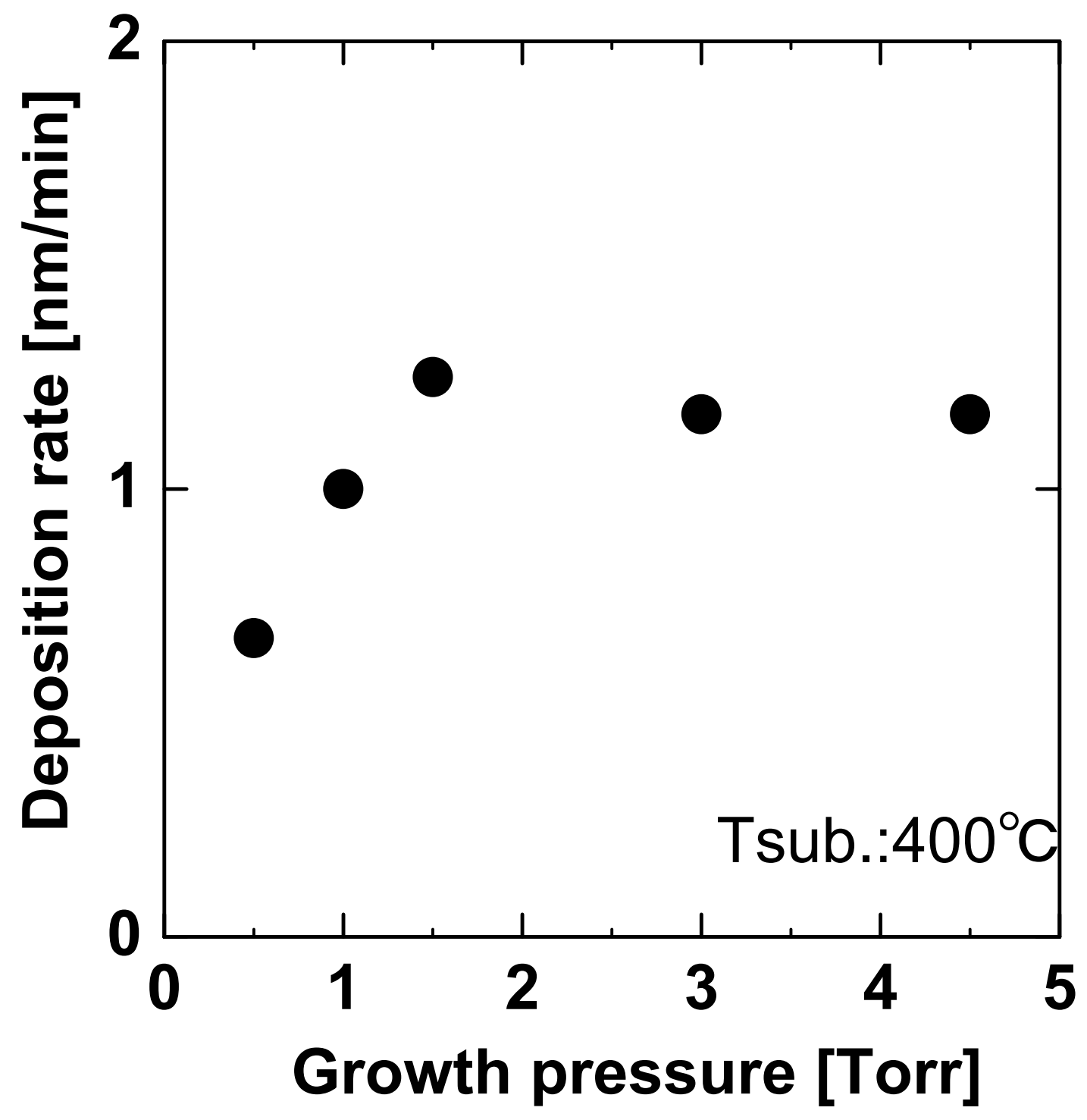


Fig. 4

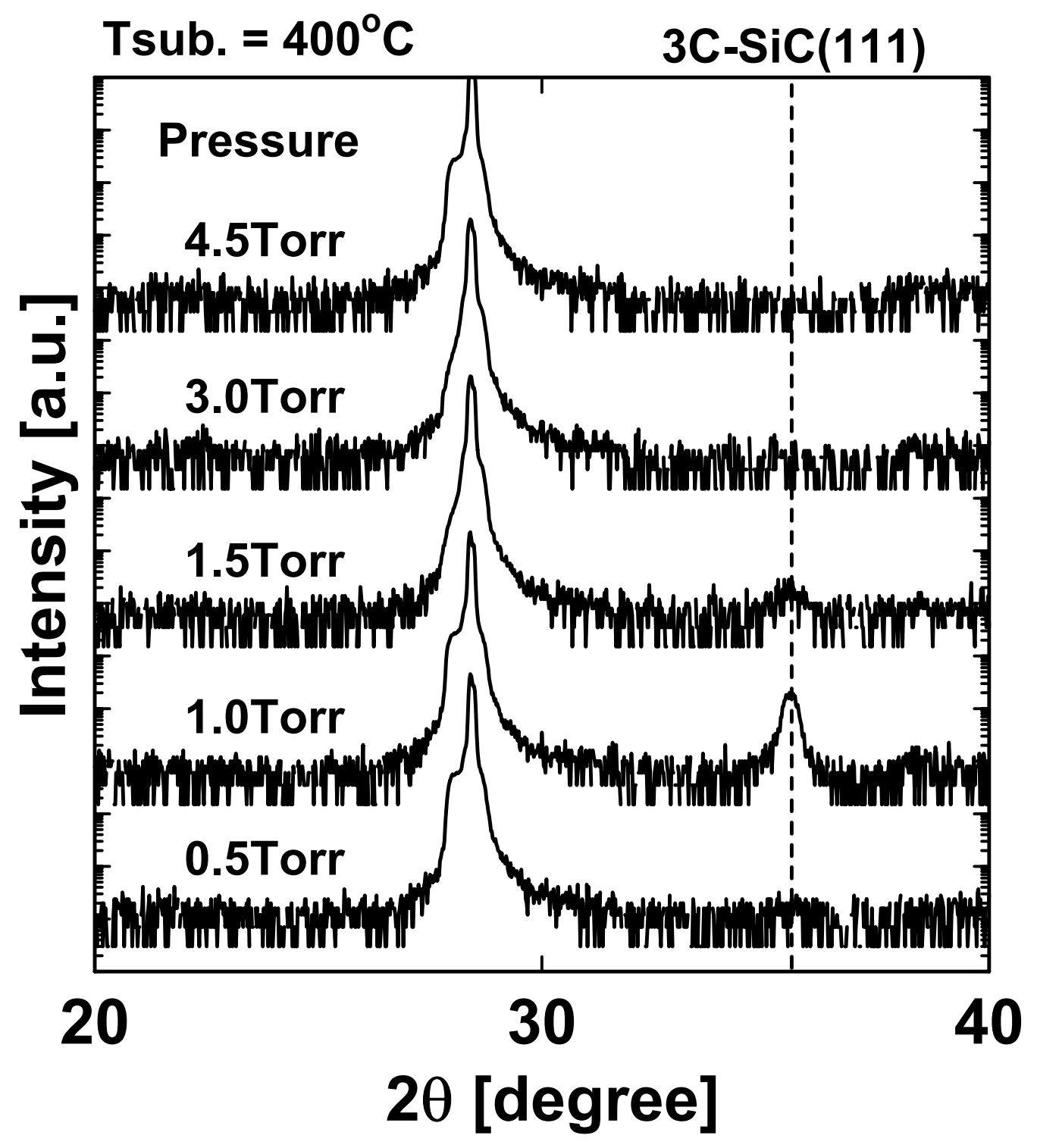


Fig. 5

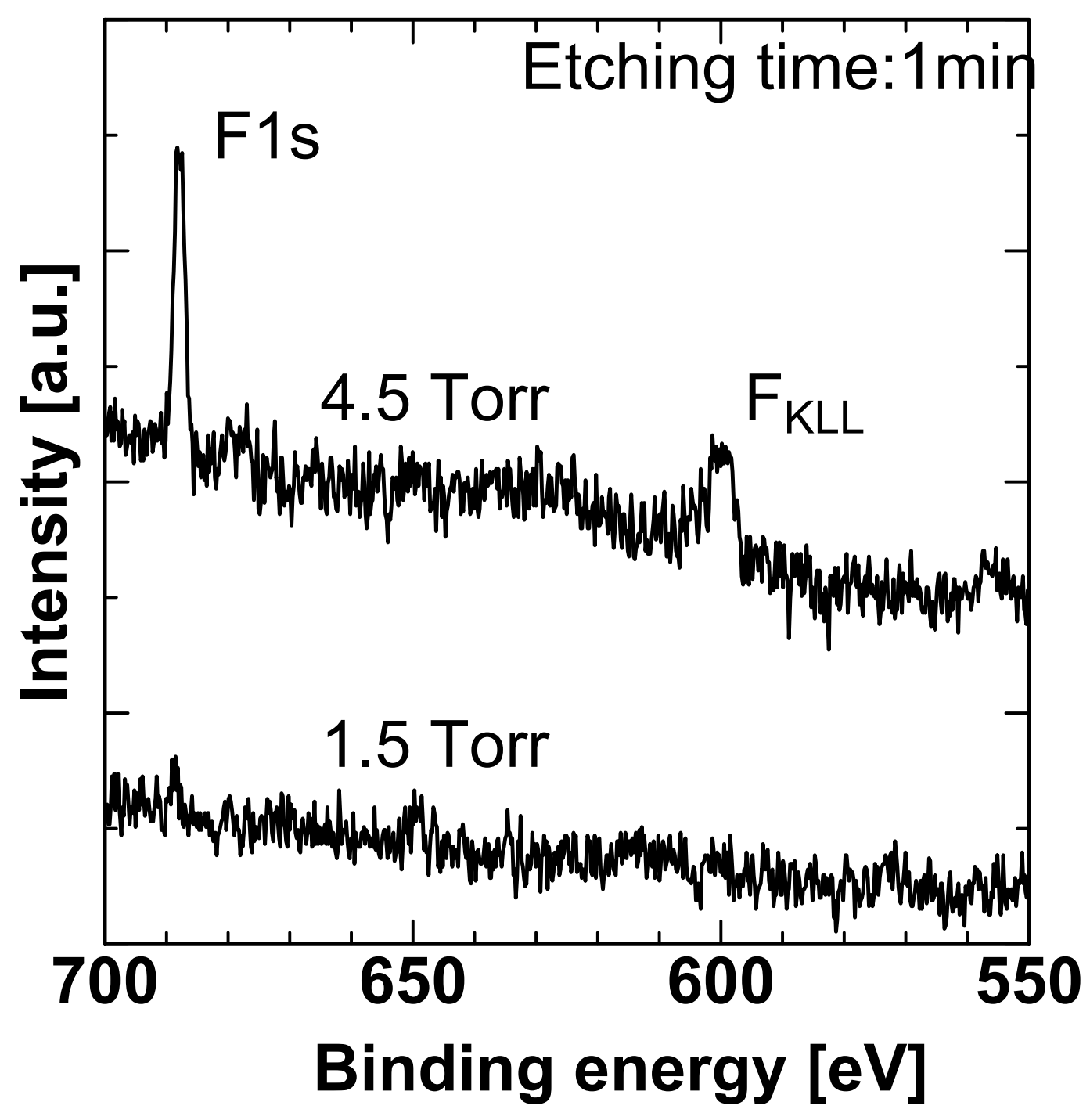

